\title{
Política pública a partir do planejamento estratégico: uma análise do sistema territorial turístico no município de Joinville (SC)
}

\author{
Cristiane Silva*
}

Faculdade Sinergia (Brasil)

\section{Romualdo Theophanes de França Junior**}

Universidade do Estado de Santa Catarina (Brasil)

\begin{abstract}
Resumo: O presente artigo realiza uma avaliação do planejamento estratégico formalizado para impulsionar o desenvolvimento do turismo no município de Joinville (SC), apropriado como ferramenta de gestão capaz de produzir subsídios para tratamento e constituição de políticas públicas para o turismo local. No contexto de uma perspectiva crítica, que busca compreender a estrutura e a estratégia adotadas como parte integrante de sua economia, o estudo compreende uma abordagem a partir do modelo de sistema territorial turístico, onde revelados os aspectos impactantes é possível estabelecer as prioridades de investimentos, seguindo o conjunto de fatores que devem ser tratados e planejados simultaneamente. Detectou-se que a ausência de integração entre a administração pública e o trade turístico tendem a impossibilitar a efetivação dos planos diretor e de marketing para o setor turístico no município, concepções importantes para o incremento da atividade.
\end{abstract}

Palavras-chave: Gestão do turismo; Território turístico; Planejamento do turismo; Políticas públicas; Planejamento estratégico.

Public policy based on strategic planning: an analysis of the land planning for tourism in the city of Joinville (SC)

Abstract: This article presents an assessment of formal strategic planning to boost the development of tourism in the city of Joinville (SC), by way of a management tool capable of producing subsidies for the treatment and constitution of public policies for the local tourism. In the context of a critical perspective that seeks to understand structure and strategy as an integral part of its economy, the study comprises an approach based on the model of land planning for tourism and how, after impact assessment has been carried out, it is possible to establish immediate integral investment priorities. It was found that the lack of coordination and cooperation between the public administration and the tourist trade tend to make it impossible to carry out the management and marketing plans for the tourism sector in the municipality, that are important concepts for the increase of activity.

Keywords: Tourism management; Tourist areas; Tourism planning; Public policies; Strategic planning.

\section{Introdução}

Historicamente o turismo deriva-se do deslocamento de pessoas de onde residem para outros locais, onde permanecem temporariamente, promovendo um fenômeno multifacetado que estimula variadas relações de natureza cultural, econômica e ambiental, numa complexa matriz de dependências e conexões.

* Doutoranda Administração pela Universidade do Vale do Itajaí (UNIVALI); Faculdade Sinergia, Brasil; E-mail: cristianesilva. oab@hotmail.com

** Doutor em Administração e Turismo pela Universidade do Vale do Itajaí - UNIVALI; Docente da Universidade do Estado de Santa Catarina, Brasil; E-mail: romaphanes@hotmail.com 
Distinguido como atividade social, o turismo origina um amplo conjunto de interesses, influenciando setores da economia e da vida cotidiana das pessoas. Assim, a atividade turística estimula no âmbito territorial intercâmbios de valores dos mais diversos, onde se destacam as entradas de divisas para um país, o prestígio das cidades e de seus gestores públicos, a contenda por recursos orçamentários, os benefícios fiscais, a criação de empregos e riquezas, a requalificação dos espaços, a produção de bens e serviços, as relações de caráter funcional e espacial, entre outros aspectos fartamente abordados em atuais pesquisas desenvolvidas pela academia. Os atrativos turísticos são igualmente diversificados, onde a título de exemplo se apontam: lazer, eventos, ecológicos, históricos e culturais. Portanto, várias outras atividades integram e abrangem o estudo sobre o fenômeno turístico, contribuindo para o seu desenvolvimento, onde respeitadamente as ações de planejamento ocupam importante papel.

Cabe registrar que os métodos e as formas de planejamento apresentam-se como ferramentas indispensáveis à sistematização e à gestão da atividade turística nas comunidades receptoras. Neste contexto, pesquisas que contemplem essa temática são de relevância para o desenvolvimento do turismo, especialmente na elaboração de planos e programas de ação. Na trajetória da abordagem, estudar as culturas locais e suas formas de apropriação territorial, figura-se como essenciais à análise das condições e limitações do turismo na área em questão, ainda que em termos teóricos (Soares; Cardozo, 2008).

O presente trabalho desenvolve-se com base no plano denominado Joinville Cidade das Flores - Planejamento Estratégico do Turismo, que apresenta como negócio desenvolver o turismo como atividade econômica, social e cultural sob a missão de transformar Joinville em destino turístico.

Para tanto, inicia-se pela abordagem teórica, vislumbrando elucidar eventuais dúvidas e demonstrar parte do entendimento bibliográfico sobre planejamento e gestão do turismo, valoração social da região empreendida, território e atrativos turísticos, entre outros aspectos correlacionados. Segue-se permeando pelo processo da compreensão do território turístico, numa perspectiva sistêmica, proposta por Santos (2006), diagnosticando o cenário do planejamento estratégico do turismo com referência as metas estabelecidas.

\section{Políticas públicas de turismo}

A política, segundo Beni (2006), é um curso de ação calculado para alcançar objetivos, ou seja, é o caminho em que se identificam as necessidades e, de acordo com os recursos disponíveis e as restrições do mercado, se traçam as direções gerais, orientando de forma específica a gestão diária do turismo.

Tem-se que as políticas públicas são próprias da organização e das decisões do governo. Assim, a política pode ser analisada como a busca para estabelecer políticas públicas sobre determinados temas, ou de influenciá-las. Por sua vez, um elemento chave do governo se refere à concepção, ao planejamento, à gestão e à avaliação das políticas públicas (Parada, 2006).

Conceitualmente, a política pública é, na sua forma mais simples, uma decisão tomada pelo governo em empreender um determinado curso da ação ou em manter o seu status quo, podendo ser definida como planos, diretrizes, regulamentos, normas e, notadamente, decisões, que expressam a intenção do poder público em intervir em determinada demanda (Silva, 2012).

No âmbito do turismo, as políticas públicas representam o caminho planejado pelos governos regionais, em parceria com as entidades representativas e a comunidade residente, para direcionar e impulsionar o desenvolvimento da atividade turística.

Para os pesquisadores Dias e Matos (2012), as políticas públicas de turismo são intervenções conscientes, intencionais, formais, racionais e estratégicas realizadas a partir do Estado, ou sob a coordenação deste, visando intervir num determinado sistema turístico, buscando direcionar seu crescimento no sentido de beneficiar toda sociedade numa perspectiva sustentável. Neste norte, o papel do Estado se torna fundamental, procurando corrigir suas falhas e reforçando seus aspectos positivos.

É preciso ter em mente que o sistema turístico, de qualquer nível que possa ser considerado (local, regional, estadual ou nacional), é um sistema aberto e que está permanentemente sujeito a influências externas (econômicas, sociais, institucionais, entre outras). Dessa feita, ele tanto influencia como é influenciado, numa sistemática cíclica e constante.

Neste contexto, Barretto (2003) leciona que o papel das políticas públicas no turismo deve ser o de propiciar o desenvolvimento harmônico da atividade, sendo de responsabilidade do Estado organizar uma estrutura jurídico-administrativa capaz de planejar e controlar os investimentos que realiza, os quais permitem o avanço da iniciativa privada, por meio da construção de equipamentos e de prestação de serviços, devendo esta administração pública criar mecanismos que assegurem o retorno em forma de benefícios à população.

Conforme identifica Dias (2003), o turismo também é um consumidor intensivo de território, portanto, é imprescindível planejar seu desenvolvimento, definindo objetivos econômicos, sem prejudicar espaços 
que devem ser protegidos, com a devida atenção à identidade da localidade. As ações de planejamento e definição de políticas adequadas tornam-se condição sine qua non nesse processo de apropriação do espaço e de todos seus elementos.

A política pública de turismo estabelece metas e diretrizes que orientam o desenvolvimento socioespacial da atividade, tanto no que tange à esfera pública como no que se refere à iniciativa privada (Cruz, 2002).

No conceito de Beni (2002), uma política de turismo deve ser estruturada levando em consideração que precisa ser norteada por três grandes condicionamentos, o cultural, o social e o econômico, aos quais pode ser agregado o ambiente.

A formulação da política de turismo deve contemplar a observação e a análise da situação de modo macro e ser capaz de orientar a tomada de decisões de longo prazo, sendo necessárias constantes atualizações, assim como o envolvimento e o compromisso dos diversos segmentos que atuam no turismo, a fim de promover e estimular a participação contínua e realista das decisões (Ruschmann; Solha, 2006).

Não resta dúvida que o papel do Estado intervindo no processo de desenvolvimento do turismo se faz necessário para a busca de respostas aos problemas inerentes a esse desenvolvimento e, principalmente, para se prevenir dos efeitos indesejados que o crescimento pode provocar, especialmente a um determinado local ou região (Silveira, 2003).

Os investimentos públicos em turismo são ferramentas significativas para gerar maior valor agregado para a região, através de políticas públicas que focam o setor (Gulcan; Kustepeli; Akgungor, 2009).

No turismo, a união de políticas públicas e investimentos da iniciativa privada em uma determinada região levam ao aumento de conhecimentos e capacidades, conseguidas nesta parceria, gerando maior estrutura e melhores serviços aos visitantes (Balalia, 2010).

O desenvolvimento da atividade turística deve ser amplamente planejado pelo Estado, nas suas esferas de governo, seguindo uma política previamente elaborada e aprovada, tal qual se evidencia na ferramenta do planejamento estratégico.

O desafio da gestão das estratégias planejadas para um destino turístico está na compreensão do papel dos vários atores envolvidos, permeando um processo dinâmico que deve observar as demandas do mercado turístico e suas variações, revisões regulares dos objetivos específicos e seus fatores associados, sempre no contexto de se estabelecer ou reavaliar as políticas públicas adotadas.

\section{O planejamento do turismo}

O conceito de planejar é amplo e envolve uma série de variáveis que se destinam a seguir um curso de ação. $\mathrm{O}$ ato de planejar define o controle da elaboração de um processo através de diretrizes, regulamentos e regras, devidamente organizados para se conquistar uma meta. Neste sentido, Molina (2005: 45) destaca que o "planejamento é um processo racional, sistemático e flexível, cuja finalidade é garantir o acesso a uma situação determinada, a qual não se poderia chegar sem ele".

O planejamento pode ser compreendido como um tipo de tomada de decisão e de elaboração de políticas que lida com um conjunto de deliberações interdependentes ou sistematicamente relacionadas e não com decisões individuais. Planejar é, portanto, apenas uma parte de um processo global de planejamento, decisão e ação (Hall, 2004).

A manipulação das variáveis do planejamento, sejam quantitativas e/ou qualitativas, é que pode facilitar a condução de ações que visam a mudança de uma situação atual ou inexistente, para uma situação factível, almejada.

A importância do planejamento é destacada por França Jr. (2014: 123), quando afirma que "sem planejamento é praticamente impossível conseguir objetivos ou terminar detalhadamente um projeto. É por intermédio do planejamento que se obtém um nível elevado de garantia para que um projeto, um trabalho ou uma atividade tenha êxito e seja coroado com sucesso".

A relação entre as funções potenciais, a compreensão das mudanças, as decisões a serem tomadas, bem como as ações executadas, são o resultado efetivo do planejamento bem concebido.

Seguindo o ensinamento de Lacombe e Heilborn (2003), o planejamento deve ser entendido como a primeira função da gestão; por meio do planejamento se pensa antecipadamente o que se pretende alcançar, determinando os meios, o tempo e os recursos necessários para concretizar tal desejo.

Quando almejado, o desenvolvimento econômico e social por meio do turismo deve-se ter em mente que para contribuir com o fortalecimento de uma região ele deve ser planejado, ordenado e bem conduzido. Implementar requer responsabilidade, vez que significa pôr em prática um projeto, programa ou plano, por meio da organização e do planejamento das ações concretas a serem executadas (França Jr., 2014). 
No contexto, o propósito do planejamento do turismo é definir metas de desenvolvimento com a expectativa de futuro, assim como os meios para alcança-los, de maneira que as transformações ocorridas no território turístico não sejam determinadas por circunstâncias fortuitas ou externas.

A discussão sobre o planejamento e a gestão do turismo tende a caminhar na busca de uma visão integrada e mais completa que recebe maior ênfase na teoria sistêmica, que vê o sistema tanto na sua totalidade quanto nas suas relações, considerando todos os seus elementos: naturais, humanos, sociais, econômicos, tangíveis e intangíveis, fixos e fluxos, forma e função (Santos, 2006). É a compreensão da complexidade e da totalidade do sistema que propiciará a criação de um cenário para as ações do planejamento, que serão, consequentemente, refletidas em todas as inúmeras e constantes interações dos elementos desse sistema.

$\mathrm{Na}$ análise do território turístico, para formalização do planejamento, os fixos são: os elementos naturais, cujas dinâmicas são resultante de processos ecológicos integrantes do sistema natural e controlados por dinâmicas não humanas; assim como, os elementos construídos resultantes das ações humanas sobre os espaços, as materializações das produções humanas. Os fluxos compreendem as dinâmicas socioculturais, que envolvem a relação do homem com os sistemas ecológicos, e as dinâmicas econômicas compostas por processos relacionados à produção, à distribuição, ao consumo e à acumulação de capital (Santos, 2006).

Tanto o processo de planejamento, como a gestão do território turístico, dependem diretamente do interesse do poder público, da vontade política, e de trazer a comunidade residente para o processo de desenvolvimento da atividade, distribuindo de forma mais equilibrada os resultados positivos.

O planejamento na atividade turística com a participação de governo, comunidade, empresários e demais stakeholders se faz importante para não ser reproduzido um cenário de crescimento sem desenvolvimento, onde existe um excesso de preocupação com o lugar e com o turista, deixando a comunidade local totalmente a margem desse processo (Burns, 2004).

Em ambientes democráticos, de complexidades sociais, econômicas e políticas, onde o planejamento linear e normativo não se mostra mais adequado, surge o planejamento estratégico, envolvendo a ordenação sistemática de um conjunto de medidas necessárias à consecução das metas almejadas, com maior rapidez e menores custos, tendentes a elevar a qualidade de vida comunitária (França Jr., 2014).

O planejamento estratégico é um importante instrumento de gestão para as organizações na atualidade. Constitui uma das mais importantes funções administrativas, e é através dele que o gestor e sua equipe estabelecem os parâmetros que vão direcionar a organização da empresa, a condução da liderança, assim como, o controle das atividades (Andion; Fava, 2002).

$\mathrm{Na}$ esfera pública também se observa a tendência de adotar o planejamento estratégico como ferramenta de resposta a um ambiente competitivo em constantes mudanças, tal como é caracterizada a atividade do turismo, o que requer que sejam continuamente revistas as formulações dos objetivos estratégicos.

O desenvolvimento de um planejamento estratégico por si só não é garantia de sucesso da atividade turística, pois escolhas erradas no processo decisório e tipos de planejamento inapropriados comprometem sua implementação. Neste sentido, se faz necessário um maior detalhamento do planejamento estratégico, ou seja, concretizá-lo em planos de ação para auxiliar no seu processo de implementação (Lai; Li; Feng, 2006).

Apesar dos benefícios oriundos das ações de planejamento estratégico, vê-se que as políticas públicas ainda se deparam em uma série de barreiras que foram mencionadas por Valls (2006) em um documento denominado Inventário das experiências mundiais em matéria de planejamentos turísticos, realizado pela UNWTO - World Tourism Organization, em 2006, em que o autor demonstra que apenas 56\% dos projetos ou planos estratégicos redigidos chegaram a ser executados, conforme demonstra o quadro I.

\section{Quadro I: Barreiras do Planejamento Estratégico de Turismo}

\begin{tabular}{|l}
\hline $\begin{array}{l}\text { - O processo de planejamento estratégico tem um custo elevado, seja qual for a identidade do promotor público } \\
\text { ou privado. Para o primeiro, dependerá da oportunidade política; para o segundo, do benefício previsto; }\end{array}$ \\
\hline $\begin{array}{l}\text { - Os interesses da população nativa, dos turistas mais ou menos frequentes, dos proprietários, dos inquilinos e } \\
\text { do resto dos agentes privados e públicos são extremamente difíceis de harmonizar; }\end{array}$ \\
\hline $\begin{array}{l}\text { - O marco de desenvolvimento que exigem os grandes grupos turísticos e as pequenas e médias empresas pode } \\
\text { chegar a ser diametralmente oposto em determinadas situações; }\end{array}$ \\
\hline $\begin{array}{l}\text { - As condições particulares de cada destino e de cada empresa desencadeiam contextos que distorcem, em } \\
\text { muitos casos, os critérios de planejamento; }\end{array}$ \\
\hline - A inércia do não-planejamento é muito cômoda e leva muitos destinos a abandonar-se às forças de mercado.
\end{tabular}

Fonte: Valls (2006). 
Diante de tais barreiras, típicas do processo clássico de elaboração de um planejamento estratégico, afirma-se que além dos papéis de promotor, de redator e de executor, o setor público deve assumir o papel de contínuo planejador, promovendo a interação entre os grupos de interesses para com as estratégias, as ações e os recursos orçamentários, facilitando o desenvolvimento do processo.

Portanto, o planejamento e a gestão da atividade turística devem partir de políticas adequadamente dimensionadas, com visão ampla, preferencialmente tomada de forma consensual entre o poder público, as empresas ligadas ao setor e a comunidade residente, estabelecendo como deve ser exercida a atividade, buscando satisfazer os desejos dos turistas sem se afastar das necessidades locais, proporcionando dispositivos de avaliação e de adequação continuadas.

\section{Procedimentos metodológicos}

Trata-se de uma pesquisa de análise bibliográfica e documental, enriquecida por levantamento de campo e informações prestadas através de pessoas responsáveis pela gestão da atividade turística do município de Joinville (SC). Em se tratando dos documentos analisados, importante ressaltar que eles foram caracterizados pelo plano denominado Joinville Cidade das Flores - Planejamento Estratégico do Turismo.

Registra-se, que se utilizou o método dedutivo, uma vez que se partiu de uma investigação não específica, razão pela qual se estabeleceu uma formulação geral e, consequentemente, apresentou-se as partes desse fenômeno, como forma de fundamentar as considerações finais, destacando os pontos mais importantes obtidos no decorrer da pesquisa.

Sendo um estudo que teve como base a descrição e a interpretação dos acontecimentos, dos grupos sociais e das interações territoriais, como também a vivência e a sensação dos próprios pesquisadores, afirmar-se que o mesmo possui caráter qualitativo, aquele que para Polit, Becker e Hungler (2004) tende a salientar os aspectos dinâmicos, holísticos e individuais vivenciados, para apreender a totalidade no contexto do que está sendo estabelecido para o fenômeno.

Sobre a ferramenta utilizada no trabalho, merece apontamento o fato de que a teoria geral dos sistemas, de Ludwig Von Bertallanfy (1967), bem como a produção de Santos (2006), a respeito da relação sistêmica e da teoria de fluxos e fixos, foi fundamental para permitir a compreensão das ações de planejamento estratégico no território turístico de Joinville (SC).

Dessa forma, todas as etapas metodológicas desenvolvidas foram propostas considerando a relação sistêmica e sua relevância no processo de compreensão da dinâmica do turismo, do ambiente da localidade estudada e todas as ações nela ocorridas, considerando o município um sistema e que o mesmo apenas pode ser compreendido a partir da correlação de suas partes componentes.

Para a análise do plano foram utilizadas como fonte de dados secundários, jornais e revistas, relatórios institucionais e internet, e como fonte de dados primários, observação in loco e informações adicionais prestadas por atores ligados à execução e gerenciamento do plano, em diferentes momentos da administração da Fundação Turística de Joinville - PROMOTUR.

Com a documentação pesquisada foi possível caracterizar o sistema turístico de Joinville, fazendo um breve relato de sua história social, cultural e econômica, além de identificar os atores envolvidos na gestão turística municipal com a interface da gestão estadual.

Para direcionar o trabalho de caracterização do território turístico de Joinville, buscou-se diagnosticar:

- Como e quando aconteceu a constituição do planejamento estratégico do turismo;

- Quais os papéis e funções desempenhados pelos atores; e

- Quais as ações estratégicas realizadas e não realizadas.

Ao trabalhar os fundamentos acima, identificaram-se os sistemas de fixos e fluxos, os quais representam os elementos naturais e os construídos pelo homem, bem como aqueles de ordem sociocultural e econômica, resultando no desenvolvimento de um sistema de informações como instrumento de análise dos vínculos gerados entre o objeto (o sistema) e a ação (o processo).

Para avaliação da implantação do planejamento estratégico, tratou-se de esmiuçar os objetivos sob a ótica da missão e do negócio, comparando-os com os levantamentos sistêmicos, estabelecendo pesos variando de 1 a 5, conforme o resultado alcançado (baixo, crítico, satisfatório, bom e ótimo), descritos em quadros de níveis obtidos para cada meta estabelecida. 


\section{O sistema turístico local}

O município de Joinville tem sua fundação registrada em 1851, a partir da vinda de imigrantes de origem alemã, suiça e norueguesa para região, que deram o primeiro passo para a sua colonização; muito embora estudos em sítios arqueológicos encontrados no município demonstrem a existência de tribos indígenas até meados do seculo XVII.

Anteriormente denominado de Colônia Dona Francisca, teve seu nome alterado para Joinville em 1852, como homenagem ao filho do rei francês Louis Phillipe, Fraçois Ferdinand Phillipe, que recebeu as terras do hoje município como dote de seu casamento com a Princesa Francisca Carolina, irmã de D. Pedro II. No início pertencente ao Município de São Francisco do Sul, Joinville obteve sua emancipação politica no ano de 1866.

Em razão de sua colonização os quais trouxeram o amor pelo meio ambiente e pela jardinagem, e graças às belezas naturais da região, a cidade ficou conhecida pela alcunha de cidade das flores. Suas ruas, praças e edifícios são ricamente decorados com cuidadosos jardins, repletos de plantas e de flores coloridas (Görresen, 2006).

A partir da década de 1930 importantes indústrias se firmaram no município, fazendo com que, já no ano de 1940, se tornasse o pólo industrial mais importante do Estado de Santa Catarina; conquista que perdura até os dias atuais.

Conbinando história e cultura, desenvolvimento e preservação da natureza, além de belas paisagens e recantos naturais, Joinville se sobressai no âmbito do turismo ecológico, de eventos e de negócios, com especial destaque para a Festa das Flores e o Festival de Dança, que acontecem anualmente.

Com o intuito de alavancar a atividade turística no município, foi instituído o Conselho Municipal de Turismo, através da Lei n. 3.169, de 21 de julho de 1995, sob a coordenação da Secretaria Municipal de Turismo e em parceria com representantes das principais entidades e segmentos do setor, tendo como finalidade planejar, estabelecer e coordenar ações voltadas à formulação da política municipal de turismo. Para tanto, a referida lei dispunha em seu art. $2^{\circ}$, item VII, a meta de elaborar o Plano Diretor de Turismo do município.

Nascido da vontade de empresários em fortalecer o setor do Turismo de Eventos na cidade, o Joinville e Região Convention \& Visitors Bureau foi fundado em abril de 1997. O foco de captar eventos para a cidade foi a prática norteadora da instituição, que a partir de 2005 passou a se chamar Joinville Costa do Encanto Convention \& Visitors Bureau (PROMOTUR, 2013).

Visando a reorganização do setor turístico no contexto da administração pública municipal, foi extinta a Secretaria Municipal de Turismo e criada a Companhia Municipal de Promoção Turística de Joinville e Região, a PROMOTUR, através da Lei n. 3.561, de 29 de setembro de 1997, que veio a adequar as entidades representativas na formação do Conselho Municipal de Turismo. Posteriormente, por força da Lei n. 4.676, de 30 de outubro de 2002, a PROMOTUR foi transformada em Fundação Turística de Joinville, contudo, mantendo as suas características funcionais.

Somente nos anos de 2000 e 2001 é que foi desenvolvido e instituído o Planejamento Estratégico do Turismo de Joinville, denominado de Joinville Cidade das Flores, calcado nos seguintes objetivos:

- Estimular investimentos públicos e privados, visando estruturar a cidade com equipamentos turísticos que sejam atração o ano inteiro;

- Captar, promover e sediar eventos; e,

- Consolidar a marca Joinville.

Com a criação das Secretarias de Estado do Desenvolvimento Regional no ano de 2003 e vislumbrando criar políticas para organização e integração regional das atividades turísticas, ação atribuída a gerencia de turismo, cultura e esporte, o Governo do Estado de Santa Catarina intentou demonstrar e ampliar seu apoio ao setor como destacada atividade da economia Catarinense.

\section{Compreensão do território turístico}

O patrimônio natural e cultural está integrado ao território e, portanto, qualquer iniciativa de desenvolvimento deve contemplar a utilização racional dos recursos dentro de uma perspectiva de um modelo de desenvolvimento sustentável (Dias, 2003).

A compreensão do sistema se materializa nos indicadores ecológicos, socioespaciais, socioculturais e econômicos. Os indicadores desse processo medem os fixos dos sistemas e os fluxos gerados por tais 
fixos. Dessa forma, os indicadores são de quantidade e de intensidade dos elementos e dinâmicas dos sistemas (Anjos et al., 2006).

Os princípios norteadores da teoria sistêmica possuem bases nos estudos de Bertallanffy (1967), incorporando avanços relacionados aos princípios fundamentais da relação entre sistema e ambiente externo, desenvolvidas por Maturana \& Varela (1995, 1997), Morgan (1996) e Capra (2002).

O território turístico, como um sistema, deve ter processos de planejamento e de gestão que ao mesmo tempo se coloquem como parte do ambiente que perturba o sistema, incrementando as possibilidades de aprendizado e de evolução, otimizando os processos de criação e inovação (Anjos et al., 2005).

Nesse contexto, a compreensão do território turístico de Joinville traz todas as informações necessárias para a efetiva e atual avaliação de uso do planejamento estratégico do turismo de Joinville, como ferramenta de gestão das políticas públicas.

\subsection{Sistema dos fixos naturais}

O município de Joinville se localiza na região nordeste de Santa Catarina, na interseção das coordenadas $26^{\circ} 18^{\prime} 05^{\prime \prime}$ de latitude sul e $48^{\circ} 50^{\prime} 30^{\prime \prime}$ de latitude oeste, ocupando uma área total de 1.134,03 quilômetros quadrados.

O relevo do município se alarga sobre terrenos cristalinos e uma área de costa deposicional. A parte oeste estende-se até os contrafortes da Serra do Mar, marginados em sentido leste por planícies de sedimentação costeira. Destaque para as Serras do Quiriri, do Rio Bonito, do Rio do Julio, do Salto, da Volta Grande e da Queimada, atingindo neste último ponto 1.325 metros de altitude. As regiões de planície são diferenciadas pelos processos sedimentares Aluvionais nas mais interioranas e marinhas na linha costeira, onde ocorrem os mangues, justamente onde se estabelece a ocupação humana (área agricultável e urbana), com altitude variando de 0 a 20 metros. Nas elevações isoladas, destaque para o Morro da Boa Vista, na área urbana, com altura de 220 metros (França Jr., 2002).

O clima local é do tipo úmido a superúmido, com temperatura média anual de $21,72^{\circ} \mathrm{C}$ e índice médio de precipitação anual de 231,23 milímetros. A umidade relativa do ar é alta, alcançando a média de $76,04 \%$. Os ventos ocorrem com maior frequência das direções leste $(26,5 \%)$ e nordeste $(17,4 \%)$, e em menor frequência das direções sudoeste $(16,3 \%)$, sudeste $(14,7 \%)$ e sul $(13,4 \%)$, sendo em baixa frequência das direções norte $(5,4 \%)$, oeste $(4,4 \%)$ e noroeste $(1,9 \%)$. No ano de 2015 , a velocidade média dos ventos atingiu o valor de $6,3 \mathrm{Km} / \mathrm{h}$ (IPPUJ, 2016).

A vegetação é caracterizada como floresta ombrófila densa, de domínio da Floresta Atlântica e, portanto, distinguida pela biodiversidade das espécies, constituindo uma vegetação densa e exuberante, com altura superior a 30 metros. No seu interior formam-se outras espécies, acomodadas a iluminação difusa, como o palmiteiro, as bromélias e as orquídeas (FUNDEMA, 2009).

De acordo com o Atlas Ambiental da Região de Joinville (2000), a hidrografia do município de Joinville apresenta-se organizada predominantemente na vertente Atlântica da Serra do Mar, cujos recursos hídricos se formam com pequena extensão e grande vazão. A formação geomorfológica associada às condições climáticas e à cobertura vegetal interfere positivamente no regime hídrico. As bacias hidrográficas do Município são a do Rio Cachoeira, do Rio Cubatão e do Rio Piraí. Com nascentes no alto das serras, entre campos de altitude e matas de galeria, os rios descem as encostas da Serra do Mar e atingem a planície quaternária, protegidos pela densa Floresta Atlântica, até desaguar na Baía da Babitonga, passando pela região dos manguezais.

Os solos estão fortemente marcados pela expressiva diferenciação da geomorfologia, caracterizando três ambientes distintos: a Serra do Mar, a região intermediária de terrenos fortemente ondulados e a planície costeira. A geologia condicionou a formação de quatro conjuntos pedológicos: os solos litólicos aparecem nas áreas de maior declividade, associado a afloramentos rochosos; após, aparecem os podzólicos, típico nos relevos ondulados; os gleissolos estão associados a planícies com drenagem deficiente, nas áreas de mangues; e, os podzóis que estão associados às baixas altitudes, junto das planícies marinhas (França Jr., 2002).

Quanto às fontes de poluição industrial, que tanto preocuparam as populações residentes da região, pode-se afirmar que estão todas localizadas e controladas. O mesmo não se pode dizer da poluição proveniente de esgotos domésticos, que se constitui no maior problema a ser enfrentado pelo município. Em que pese à responsabilidade de cada cidadão, a solução dependerá de forte determinação política, com ações técnicas específicas e onerosas.

\subsection{Sistema dos fixos construídos}

Os principais acessos do município de Joinville são originados a partir da rodovia BR-101, sob jurisdição federal. A rede viária municipal conta com 1.810,41 quilômetros, onde 314,01 quilômetros 
são estradas vicinais e 1.496,40 quilômetros vias urbanas, das quais 1.062,65 quilômetros estão pavimentadas. Partindo da área central, o sistema viário se expande na forma radial de penetração aos bairros. A cidade é servida também por vias de ligações diretas com os municípios de Guaramirim, São Bento do Sul, Araquari e São Francisco do Sul, por meio das rodovias estaduais (SEINFRA, 2015).

O transporte coletivo atende a todos os bairros através do sistema de integração física e temporal operado por duas empresas, envolvendo a estrutura física de 10 estações da cidadania e 12 estações de transbordo. Transportando em média 115 mil passageiros por dia, resultando no índice de 1,87 passageiros por quilometro rodado, que se ocupa de 265 linhas regulares de transporte, sendo: 221 linhas alimentadoras, 21 linhas interestações e 23 linhas troncais, transportando em média 115 mil pessoas por dia (IPPUJ, 2016).

O ramal ferroviário que liga Joinville ao Porto de São Francisco do Sul, inaugurado em 1906, serviu ao transporte de passageiros até o ano de 1991, e atualmente destina-se exclusivamente ao transporte de cargas, cuja operação é realizada pela América Latina Logística, no regime de concessão federal. Com obras já contratadas, o ramal será modificado para contornar a área urbana.

Para atender ao transporte intermunicipal e interestadual de passageiros, a cidade se utiliza da Estação Rodoviária Harold Nielson que possui área total construída de 6.050 metros quadrados, distribuídos em 2 pavimentos e com a seguinte distribuição interna: 24 plataformas destinadas ao embarque e desembarque, 20 lojas de comercialização de passagens, 2 salas de espera climatizadas, que totalizam 210 lugares sentados, banheiros masculino e feminino, praça de alimentação com espaço para 4 lanchonetes, loja de presentes e artesanatos, revistaria e tabacaria, estacionamento coberto para carros e motos. Cabe destacar que todas as áreas internas atendem as exigências das normas de acessibilidade. No ano de 2015 apresentou movimentação média de 2.318 passageiros por dia, o que representou uma queda de $13 \%$ em relação ao ano anterior (SEINFRA, 2015).

O aeroporto de Joinville, Lauro Carneiro de Loyola, possui área total construída de 4.000 quilômetros quadrados e pista de manobras com 1.640 metros de comprimento, representando um importante meio de transporte para a região nordeste do Estado. Estando a apenas 13 quilômetros de distância do centro da cidade, o aeroporto destina-se à aviação doméstica e tem capacidade para atender 500.000 mil passageiros por ano. Desde o ano de 2014 encontra-se equipado com o sistema de aproximação por instrumentos (ILS), reduzindo significativamente a quantidade de cancelamento de voos devido ao mau tempo. Seus usuários possuem perfil executivo, empresarial e turístico de eventos. O aeroporto atingiu no ano de 2015 a seguinte movimentação operacional: 519.062 passageiros, $1.175 .273 \mathrm{Kg}$ de cargas e 3.166 decolagens geradas por 11 voos diários (INFRAERO, 2016).

O Rio Cachoeira, hoje bastante poluído, foi uma importante via no transporte de cargas, sendo atualmente direcionado como hidrovia para servir ao transporte de passageiros entre o centro de Joinville e o centro da cidade de São Francisco do Sul. O canal do rio entre o bairro Espinheiros e a Baia da Babitonga destaca-se no setor turístico, servindo como meio para passeios marítimos, além de ser um elo entre os portos de Itapoá e São Francisco do Sul.

O regime urbanístico de uso, ocupação e parcelamento do solo, instituído pela Lei Complementar n. 312/2010, é fundado no sistema de zoneamento territorial, abarcando os 35 bairros da cidade e os 4 distritos, ficando perceptível a descontinuidade do tecido urbano. No que tange a rede viária, comporta boa integração entre os bairros e os distritos, servindo como principal fator de delimitação da área urbana do município, inclusive permitindo a centralização de cada bairro e dos distritos (IPPUJ, 2016).

A proliferação de loteamentos, ocorrida entre as décadas de 70 e 90, sem observar as características do solo, vinculadas ao alto crescimento demográfico e as invasões de terras, resultou em um meio urbano desordenado, especialmente no que tange as agressões ao meio natural e ao sistema de saneamento municipal (França Jr., 2002). Em que pese à evolução das soluções aplicadas a partir de 2002, ainda existem passivos que devem ser tratados no contexto ambiental.

As edificações e os espaços livres dão forma ao território, em que é possível se verificar: áreas menos densas e sem verticalizações situadas próximo ao mar e a serra, formando extensões de espaços livres e de vazio urbano, e áreas de maior densidade, com forte tendência à verticalização, situada na área central, onde os espaços livres já encontram restrições para inserção de áreas públicas de lazer (França Jr.; Silva, 2013).

Com diversificação cultural e tradições artísticas, reminiscência já dos primeiros imigrantes, o acervo histórico da cidade pode ser visto em sua memória edificada, com destaque para: Alameda Brüstlein, Cemitério dos Imigrantes, Pórtico e Moinho no acesso pela rua XV de novembro, Estação Ferroviária, Casas de Enxaimel, Mercado Público, Mirante, Gruta da Imaculada Conceição, Arquivo Histórico, Galeria Municipal de Artes Victor Kursancew, Centreventos Cau Hansen, Estrada Bonita, 
Recanto Jativoca, Parque Zoobotânico, Museu da Bicicleta, Museu da Fundição, Museu Casa Fritz Alt, Museu Arqueológico de Sambaqui, Parque Ecológico Morro do Finder, Museu Nacional de Imigração e Colonização, Orquidário Boa Vista, Museu Nacional do Bombeiro, Sede da Sociedade Lírica, Museu da Indústria, Complexo Cultural Antarctica, Museu de Arte Ottokar Doerffel, Igreja da Paz, Catedral Diocesana, Sede da Sociedade Harmonia Lyra, Teatro Juarez Machado e Escola do Teatro Bolshoi no Brasil (Cunha; Bastian, 2009).

\subsection{Sistema dos fluxos sociais}

Tradicionalmente chamada de Cidade dos Príncipes, os colonizadores que chegaram ao município de Joinville na metade do século XIX não ostentavam riquezas, nem descendiam de berços nobres, tendo uma vida bastante simples e de muito trabalho, fixando ali as suas origens e dando início à que atualmente é a maior cidade do Estado de Santa Catarina (Gorresen, 2006).

Fundada para ser uma colônia agrícola, dinamicamente a cidade transformou-se em centro econômico, político e cultural. Dentre seus primeiros colonizadores se encontravam alguns capitalistas, empregadores, artesãos, oficiais e acadêmicos, homens cultos e inteligentes, senhoras e senhores que promoveram intensa repercussão na colônia. O fator humano apresentou-se como diferencial nessa mudança, em que a presença de pessoas de origem não agrícola, o assentamento em minifúndios, a qualificada mão de obra e um mercado consumidor favorável para produtos manufaturados, favoreceram o desenvolvimento industrial da hoje Manchester catarinense (Gehlen, 2011).

Segundo o IPPUJ (2016), a evolução demográfica da região pode ser caracterizada basicamente por três fenômenos: a forte reversão da população rural em urbana, a explosão demográfica do município de Joinville após a década de 1970, fazendo com que, atualmente, o município represente o maior aglomerado urbano no estado, e as consecutivas emancipações dos municípios, sendo que, dos três municípios existentes na década de 1920, apenas o município de Joinville não diminuiu sua área territorial.

O censo 2010, realizado pelo IBGE, registrou a população de Joinville com 515.250 habitantes, representando uma taxa de crescimento anual de 1,6\%, mantendo o status de cidade mais populosa de Santa Catarina, aonde a população urbana chegou a 96,59\%, superando a média de urbanização no Estado que é de 78,7\%. A densidade demográfica está em 454 habitantes por quilômetro quadrado. Em projeção realizada pelo IPPUJ (2016), com taxa de crescimento de 1,343\%, estima-se que em 2015 o município possuía 562.151 habitantes.

Apresentando IDH - Índice de Desenvolvimento Humano de 0,857, Joinville ocupa a $13^{\text {a }}$ posição Nacional. O município acumulou avanço em torno de $40 \%$ em seu desenvolvimento humano a partir de 1970, onde se destacam as seguintes referências: taxa de mortalidade infantil de 8,76\%, esperança de vida ao nascer de 76,6 anos, índice de pobreza em $28 \%$ e índice de desenvolvimento familiar de 0,57; e seu maior avanço nos últimos 10 anos foi registrado na dimensão longevidade (SEBRAE, 2015).

Nos aspectos educacionais, dos 126.583 alunos matriculados em 2014, sem computar os cursos universitários, a rede pública atendeu $70,28 \%$. O índice de analfabetismo é de 1,88\% e o de formação em curso superior atingiu 11,27\%. A rede de ensino no município é formada por 323 unidades, das quais 188 escolas são de caráter público (IPPUJ, 2016).

Com base em informação fornecida pela Secretaria de Estado da Segurança Pública, ocorreram em Joinville 319 mortes por causas violentas no ano de 2015, sendo 42,37\% com ocorrência no trânsito. O setor está sob atribuição da polícia militar estadual; no entanto, o efetivo de policiais não é suficiente para cobrir rondas de 24 horas em todo território. A estratégia operacional de segurança conta com câmeras de vídeo que atualmente monitoram $20 \%$ da área urbana.

Enquanto os serviços de coleta de lixo, fornecimento de energia elétrica, abastecimento de água potável e telecomunicações apresentam índices que ultrapassam a média de $99 \%$ de atendimento, o sistema de esgoto sanitário vem sendo implantado ainda em ritmo lento e atualmente atende apenas 29,06\% da população (IPPUJ, 2016).

\subsection{Sistema dos fluxos econômicos}

Os primeiros movimentos econômicos do município originaram-se da agricultura e essa produziu as primeiras atividades industriais, onde se incluem os engenhos de açúcar, os moinhos de arroz, de milho, de mandioca e de araruta. Na década de 1880 surgiram as primeiras indústrias têxteis e metalúrgicas. Durante quatro décadas a produção e comercialização da erva-mate impulsionaram a economia local. Em 1926, com a aplicação do capital acumulado durante décadas pelos imigrantes, percebe-se o fortalecimento do setor metal-mecânico. Entre as décadas de 1950 e 1980 Joinville viveu um grande 
crescimento com o conflito mundial, quando o Brasil deixou de receber produtos industrializados da Europa. Isso fez com que o município se transformasse em um dos principais polos industriais do país, recebendo, por isso, a denominação de Manchester Catarinense, referência à cidade inglesa de mesmo nome (Cunha; Bastian, 2009).

Sem perder seu forte perfil industrial, a classe comercial, de forma muito habilidosa, passou a influir e transformar o ambiente, liderando a política e direcionando suas iniciativas para a instalação das infraestruturas básicas, razão que levou a uma aceleração no processo de urbanização (Gehlen, 2011).

Impulsionado por seu parque industrial, o município de Joinville no ano de 2013 atingiu 21,98 bilhões de dólares de produto interno bruto - PIB, o que responde por 11,8\% do PIB estadual. Atingido pela crise econômica e política do Brasil, a balança comercial em 2015 apresentou um volume de exportações de 1.062.901.991 dólares, com saldo comercial negativo de 563.381.880 dólares, representando valor em queda fiscal de 5,39\% (IPPUJ, 2016).

Em relação à movimentação do mercado de trabalho, verifica-se um histórico positivo entre os anos de 2004 e 2014 com média anual de 6,6\% na relação entre admissões e demissões. No entanto, no ano de 2015 o mesmo indicador se mostrou atingido pelas dificuldades econômicas nacionais, experimentando saldo negativo de 5,29\%, com a população economicamente ativa de 76,7\% (MTE, 2016).

A produção rural apresenta como principais cultivos o palmito, a banana, a cana de açúcar e o arroz, com 8,96\%, 4,84\%, 2,81\% e 1,91\% da produção estadual, respectivamente. A pecuária, pouco difundida, vem apresentando gradativa redução na produção, onde se destacam a criação de caprinos, galinhas e bovinos, com $5,56 \%, 0,48 \%$ e $0,41 \%$ da produção estadual, respectivamente (SEBRAE, 2015).

No setor de turismo, a PROMOTUR, tendo como base o ano de 2014, estima que Joinville recebeu 310.000 turistas, com índice médio de permanência no município de 2,74 dias; a rede hoteleira obteve taxa de ocupação de 50,8\%, e o gasto médio diário alcançou 79,65 dólares. Enquanto o turismo de eventos vem apresentando gradativa redução percentual, o turismo rural permanece estável, sendo responsável, inclusive, por um pequeno aumento da população rural.

\section{Avaliação do planejamento estratégico do turismo}

Para constituição do planejamento estratégico do turismo em Joinville foi acionado o Conselho Municipal de Turismo, cujo trabalho foi desenvolvido em três diferentes níveis de atuação. O trabalho individual constou de questionário preenchido pelos participantes, envolvendo as diferentes etapas do planejamento da atividade, que serviram de subsídios para as etapas seguintes. Para o trabalho em grupo, os participantes foram divididos em quatro conjuntos temáticos para construção das ideias e das opiniões. A finalização deu-se em trabalho plenário, onde cada grupo apresentou suas perspectivas aos demais participantes, que após debate foram consolidadas no plano.

Denominado Joinville Cidade das Flores, o Planejamento Estratégico apontou como negócio desenvolver o turismo como atividade econômica, social e cultural, dentro da missão de transformar Joinville em destino turístico.

A implantação e administração do plano ficaram a cargo do próprio Conselho Municipal de Turismo, com destaque às seguintes responsabilidades: atuar como órgão deliberativo, supervisionando as ações da PROMOTUR; realizar reuniões periódicas de acompanhamento e semestrais de avaliação; e indicar o Diretor Presidente da PROMOTUR, órgão executor das ações propostas.

Das investigações realizadas, percebeu-se que o Conselho Municipal de Turismo não tem atuado, sequer é ouvido ou chamado a participar da formalização das políticas para o setor. Todas as tratativas são deliberadas pela própria PROMOTUR, quando muito colhendo opinião do Joinville Costa do Encanto Convention \& Visitors Bureau.

Visando identificar e planificar as avaliações realizadas foram desenvolvidos quadros de pontuação por níveis (baixo, crítico, satisfatório, bom e ótimo) para as metas estabelecidas nas ações estratégicas e nos objetivos específicos. A pontuação é resultado do que cada meta conquistou desde que foi consolidada no planejamento estratégico do turismo, com base nos documentos pesquisados, nas entrevistas realizadas e, principalmente, no levantamento dos sistemas de fixos e fluxos do território turístico de Joinville. 
Quadro II: Avaliação das Ações Estratégicas

\begin{tabular}{|l|c|l|l|c|}
\hline \multicolumn{1}{|c|}{ Caráter político } & Índice & \multicolumn{1}{c|}{ Caráter técnico } \\
\hline Fortalecer a Promotur e o Convention Bureau & 2 & Elaborar o Plano Diretor de Turismo & 1 \\
\hline Consolidar o poder do Conselho de Turismo & 1 & Elaborar e implantar o Plano de Marketing & 1 \\
\hline Conscientizar lideranças públicas e privadas & 2 & Aprimorar a profissionalização do setor & 2 \\
\hline Envolver e comprometer a comunidade & 1 & $\begin{array}{l}\text { Avaliar e pesquisar periodicamente as ações } \\
\text { desenvolvidas }\end{array}$ & 1 \\
\hline $\begin{array}{l}\text { Viabilizar parcerias entre o poder público e a } \\
\text { iniciativa privada }\end{array}$ & 3 & $\begin{array}{l}\text { Solidificar a identidade Joinville Cidade das } \\
\text { Flores }\end{array}$ & 3 \\
\hline $\begin{array}{c}\text { Legenda } \\
\text { 2- Nível baixo }\end{array}$ & & \multicolumn{2}{|c|}{$\begin{array}{c}3-\text { Nível satisfatório } \\
\text { 4- Nível bom } \\
5-\text { Nível ótimo }\end{array}$} \\
\hline
\end{tabular}

Fonte: Os Autores (2016).

\section{Quadro III: Avaliação dos Objetivos Específicos}

\begin{tabular}{|c|c|c|c|}
\hline Mercadológico & & Operacional/Serviço & \\
\hline Objetivo & Índice & Objetivo & Índice \\
\hline $\begin{array}{l}\text { Alavancar recursos para o Convention \& } \\
\text { Visitors Bureau }\end{array}$ & 3 & $\begin{array}{l}\text { Elaborar e implantar o Plano de } \\
\text { Capacitação }\end{array}$ & 1 \\
\hline $\begin{array}{l}\text { Intensificar a divulgação do calendário de } \\
\text { eventos }\end{array}$ & 2 & $\begin{array}{l}\text { Envolver no comitê representantes de } \\
\text { entidades }\end{array}$ & 1 \\
\hline Elevar a participação do turismo no PIB & 1 & Levantar as atividades desenvolvidas & 3 \\
\hline Aprimorar sinalização turística e de acesso & 1 & $\begin{array}{l}\text { Levantar informações através de pesquisas } \\
\text { mercadológicas }\end{array}$ & 1 \\
\hline $\begin{array}{l}\text { Estimular o turismo de compras, rural, } \\
\text { receptivo, eventos e lazer }\end{array}$ & 1 & $\begin{array}{l}\text { Estabelecer cronologia para referendar/ } \\
\text { atualizar a capacitação }\end{array}$ & 1 \\
\hline $\begin{array}{c}\text { Legenda } \\
1 \text { - Nível baixo } \\
2-\text { Nível crítico }\end{array}$ & \multicolumn{3}{|c|}{$\begin{array}{l}3 \text { - Nível satisfatório } \\
4 \text { - Nível bom } \\
5 \text { - Nível ótimo }\end{array}$} \\
\hline
\end{tabular}

Fonte: Os Autores (2016).

\section{Quadro IV - Avaliação das Metas de Infraestrutura}

\begin{tabular}{|c|c|c|c|}
\hline \multicolumn{4}{|c|}{ Obras e serviços } \\
\hline Meta & Índice & Meta & Índice \\
\hline $\begin{array}{l}\text { Transformar a Expoville em pavilhão de feiras } \\
\text { e negócios }\end{array}$ & 5 & $\begin{array}{l}\text { Estimular a preservação do patrimônio } \\
\text { histórico e do meio ambiente }\end{array}$ & 4 \\
\hline $\begin{array}{l}\text { Viabilizar a construção do Centro de } \\
\text { Convenções no Centreventos Cau Hansen }\end{array}$ & 5 & $\begin{array}{l}\text { Criar projeto turístico e ambiental do morro } \\
\text { do Boa Vista; integrando-o como Parque } \\
\text { Zoobotânico }\end{array}$ & 1 \\
\hline $\begin{array}{l}\text { Tratamento urbanístico na rua XV de } \\
\text { Novembro consolidando-a como principal eixo } \\
\text { de acesso turístico }\end{array}$ & 3 & $\begin{array}{l}\text { Recomendar estudo de valorização } \\
\text { urbanística do Centreventos Cau Hansen }\end{array}$ & 1 \\
\hline $\begin{array}{l}\text { Remodelar o pórtico da rua XV de Novembro } \\
\text { em conjunto com o moinho }\end{array}$ & 4 & Ampliar e melhorar o aeroporto & 3 \\
\hline $\begin{array}{l}\text { Criar sinalização, paradas e estacionamentos } \\
\text { para ônibus de turismo }\end{array}$ & 2 & Criar um pórtico de acesso sul & 1 \\
\hline $\begin{array}{l}\text { Revitalizar a estação ferroviária como ponto } \\
\text { turístico }\end{array}$ & 3 & $\begin{array}{l}\text { Implantar programa de instalação de } \\
\text { sanitários }\end{array}$ & 1 \\
\hline Viabilizar o portal do mar/trapiche & 2 & $\begin{array}{l}\text { Apoiar projeto de sinalização turística da } \\
\text { BR-101 }\end{array}$ & 1 \\
\hline \multicolumn{2}{|l|}{$\begin{array}{c}\text { Legenda } \\
1 \text { - Nível baixo } \\
2 \text { - Nível crítico }\end{array}$} & \multicolumn{2}{|l|}{$\begin{array}{c}3 \text { - Nível satisfatório } \\
4 \text { - Nível bom } \\
5 \text { - Nível ótimo }\end{array}$} \\
\hline
\end{tabular}

Fonte: Os Autores (2016). 
Buscando estabelecer a análise no que concerne a avaliação das estratégias nos caráteres político e técnico, a avaliação dos objetivos específicos nas esferas mercadológica e operacional, e a infraestrutura em suas metas de obras e serviços, apresentam-se abaixo alguns aspectos como contraponto ao que vem sendo estabelecido pela municipalidade frente ao negócio do planejamento estratégico do município, que é desenvolver o turismo como atividade econômica, social e cultural, dentro da missão de transformar Joinville em destino turístico.

Sendo interesse do planejamento o desenvolvimento do turismo nos âmbitos econômico, social e cultural, é imprescindível envolver, nesse processo, todo o trade local, buscando nele inserir a comunidade autóctone, prezando por suas características culturais.

Trata-se, inclusive, da premissa básica de proposta sustentável no âmbito do turismo. Dentro dessa perspectiva e articulação é que se conseguirá, de alguma maneira, através de boas ações, de propostas e de gestão, a obtenção dos resultados almejados e previstos.

Não obstante, porém, o que se observa nos quadros que resultaram do estudo, em especial aqueles aspectos que tiveram resultados baixos, é que não se deu de forma efetiva a consolidação do poder do Conselho Municipal de Turismo, o que representa uma perspectiva negativa. Somente com um Conselho de Turismo apoderado é que determinadas temáticas podem ser discutidas, refletidas, participadas e colocadas em prática, através das ações de governo. Da mesma forma, está latente que até o momento não há o envolvimento da comunidade e dos representantes de comitês.

Excluir a comunidade do processo de desenvolvimento turístico de uma localidade pode ser considerado um dos maiores entraves no desenvolvimento econômico local, justamente porque é a sociedade a responsável pelo acolhimento e hospitalidade daqueles que, pelo turismo, trazem renda à localidade. Tal perspectiva parece demonstrar o paradoxo existente entre o discurso do planejamento e sua efetivação.

Da mesma forma, a pesquisa detectou a ausência de elaboração do plano diretor e de marketing, tão essenciais no processo do planejamento estratégico para o turismo local. Elementos que norteiam as ações de gestão do turismo são imprescindíveis num processo de aprimoramento do desenvolvimento.

Verificou-se, ainda, a ineficácia na criação de infraestruturas voltadas à implementação da atividade turística. As poucas conquistas são pontuais, com expressão na realização de eventos. A infraestrutura destinada a garantir acessibilidade aos atrativos, conforto e segurança aos turistas está longe de atender a potencialidade turística, proposta pelos aspectos histórico e cultural do município.

Os parâmetros do estudo que se demonstraram críticos carecem ser repensados, justamente pelo fato de que a proposta de planejamento compreendida dentro de uma realidade sistêmica e através da relação dos fluxos e fixos depende, exclusivamente, da integração de todas as esferas, devidamente assistidas pelas políticas públicas e colocadas em prática por ações de planejamento eficientes e eficazes.

\section{Considerações finais}

A ausência de prioridade política para o desenvolvimento do turismo e a falta de participação do Conselho Municipal de Turismo, provocada pela própria administração pública, permite afirmar que a missão de transformar Joinville em destino turístico ainda está longe de acontecer. Fato corroborado no fraco desempenho alcançado nas avaliações das ações estratégicas e dos objetivos específicos, o que mantém estagnado a elaboração do plano diretor e do plano de marketing para o turismo.

As premissas básicas do planejamento estratégico definem que o Diretor Presidente da PROMOTUR seja sugerido pelo trade, o que não é respeitado, sequer colhida opinião, o que vem provocando o afastamento e o apoio dos atores da iniciativa privada. Será fundamental rever a premissa ou estabelecê-la como item importante da política pública no setor.

A interface de participação do Governo Estadual, especialmente voltada a se envolver na integração do turismo regional, através da Secretaria de Estado do Desenvolvimento Regional, ainda é muito tímida e se fixam apenas no recebimento e na aprovação de projetos de eventos que visam à alocação de recursos.

Há por parte do poder público um envolvimento para manter os eventos e os roteiros turísticos existentes, especialmente os ligados ao setor artístico, mas pouco ou quase nada é realizado para captação e criação de novos projetos, o que poderia ser conquistado com maior envolvimento regional.

As quedas constatadas nos fluxos econômicos do município são um convite para dedicar boa atenção ao aproveitamento do potencial turístico para implementar nova cadeia de desenvolvimento socioeconômico.

Joinville conhecida como a Cidade das Flores, dos Príncipes, das Bicicletas, Manchester Catarinense e Pólo Industrial Nacional, detém um patrimônio histórico, cultural e artístico, possuindo belezas naturais e edificadas preservadas, compondo uma paisagem turística bastante favorável ao seu desenvolvimento, o que foi observado e caracterizado nos estudos dos sistemas de fixos e fluxos. O que lhe falta é a determinação para cumprir o planejamento estratégico desenvolvido, observando a constante 
avaliação e adequação das metas, de forma integrada e sistêmica, para implantar e desenvolver o território turístico com adequadas ferramentas de gestão.

\section{Bibliografia}

Andion, M. C.; Fava, R.

2002. "Planejamento Estratégico". Coleção Gestão Empresarial. v. 2, n. 3. Curitiba: Associação Franciscana de Ensino Senhor Bom Jesus.

Anjos, F. A.; Anjos, S. J. G.; Barros, R. B.; Zanchi, C.

2005. "Processo de planejamento e gestão de territórios turísticos: princípios norteadores de uma proposta". Revista Turismo-Visão e Ação. Itajaí.

Anjos, F. A.; Anjos, S. J. G.; Rados, G. J. V.

2006. "O Processo de compreensão do sistema territorial turístico para o planejamento e a gestão integrados". Revista Turismo-Visão e Ação. Itajaí.

Atlas Ambiental da Região de Joinville.

2000. Complexo hídrico da Baía da Babitonga. Joinville (SC).

Balalia, A. E.

2010. "Cooperation Between the public and private sector-key element for travel \& tourism in the context of the global economic crisis". Tourism \& Hospitality Management.

Barretto, M.

2003. Turismo, políticas públicas e relações internacionais. Campinas: Papirus.

Beni, M. C.

2006. Política e planejamento de turismo no Brasil. São Paulo: Aleph.

Beni, M. C.

2002. Análise estrutural do turismo. São Paulo: Senac - São Paulo.

Bertalanffy, L. V.

1967. Teoria geral dos sistemas. Petrópolis: Vozes.

Burns, P. M.

2004. "Tourism planning a third way?" Annals of Tourism Research. London.

Capra, F.

2002. As conexões ocultas: ciência para uma vida sustentável. São Paulo: Cultrix.

Cruz, R. C.

2002. Política de turismo e território. São Paulo: Contexto.

Cunha, D.; Bastian, N.

2009. Memória afetiva de Joinville. Joinville: Todaletra.

Dias, R.

2003. Planejamento do turismo: política e desenvolvimento do turismo no Brasil. São Paulo: Atlas.

Dias, R., Matos, F.

2012. Políticas Públicas: princípios, propósitos e processos. São Paulo: Atlas.

França JR., R. T.

2002. Levantamento de dados e informações para mapeamento geotécnico da área urbana de Joinville.

107 fls. Dissertação (Mestrado em Engenharia Civil) - Universidade Federal de Santa Catarina (UFSC), Florianópolis, SC.

França JR., R. T.

2014. A mobilidade turística no processo de planejamento da logística de transportes de Santa Catarina. $253 \mathrm{fls}$. Tese (Doutorado em Administração e Turismo) - Universidade do Vale do Itajaí (UNIVALI), Biguaçu, SC.

França JR., R. T.; Silva, C.

2013. "A influência da Alameda Brüstlein na paisagem turística de Joinville (SC)". Revista TURyDES, v. 6 (15): 1-12. Málaga.

FUNDEMA - Fundação Municipal do Meio Ambiente.

2009. Dados do ambiente natural. Secretaria da Agricultura e Meio Ambiente de Joinville. Joinville.

Gehlen, J.

2011. O século singular: participação empresarial na formação de Joinville. Joinville: Editora Letradágua. Görresen, H.

2006. Joinville: a cidade. Joinville: Ana Paula.

Gulcan, Y.; Kustepeli, Y.; Akgungor, S.

2009. Public policies and development of the tourism industry in the aegean region. European Planning Studies. London. 
Hall, C. M.

2004. "Planejamento turístico: políticas, processos e relacionamentos". São Paulo: Contexto.

INFRAERO - Empresa Brasileira de Infraestrutura Aeroportuária.

2016. Relatório de Movimento Operacional da Rede. Brasília.

IPPUJ - Instituto de Planejamento e Pesquisa Urbana Sustentável de Joinville

2016. Joinville Cidade em Dados 2016. Joinville (SC).

Lacombe, F. J. M.; Heilborn, G. L. J.

2003. Administração: princípios e tendências. São Paulo: Saraiva.

Lai, K.; LI, Y.; Feng, X.

2006. Gap between tourism planning and implementation: a case of China. Tourism Management.

Amsterdam: Elsevier.

Maturana, R. H.; Varela F. J.

1997. De máquinas e seres vivos: autopoiese - a organização da vida. Porto Alegre: Artes Médicas.

Maturana, R. H.; Varela, F. J.

1995. A árvore do conhecimento. Campinas: Editorial Psy II.

Molina, S.

2005. Turismo metodologia e planejamento. Bauru, SP: Edusc.

Morgan, G.

1996. Imagens da organização. São Paulo: Atlas.

MTE - Ministério do Trabalho e Emprego

2016. Programa de disseminação de estatística do trabalho. Brasília (DF).

Parada, E. L.

2006. "Política y políticas públicas". In: Saravia, E; Ferrarezi, E. (Org.). Políticas públicas. Coletânea.

Brasília: ENAP, 2006. v. 1. p. 67-96.

Polit, D. F.; Becker, C. T.; Hungler, B. P.

2004. Fundamentos de Pesquisa: métodos, avaliação e utilização. Porto Alegre: Artmed.

PROMOTUR, Fundação Turística de Joinville e Região.

2013. Dados do turismo em Joinville. Joinville (SC).

Ruschmann, D.; Solha, K. T.

2006. Planejamento turístico. Barueri, SP: Manole.

Santos, M.

2006. A natureza do espaço: técnica e tempo, razão e emoção. 4. ed. 2. reimpr. - São Paulo: Editora da

Universidade de São Paulo.

SEBRAE - Serviço de Apoio a Micro e Pequenas Empresas.

2015. Santa Catarina em dados. Florianópolis (SC).

SEINFRA - Secretaria de Infraestrutura Urbana do Município de Joinville.

2015. Informações Operacionais de Infraestrutura. Joinville (SC).

Silva, C.

2012. A elaboração da agenda de políticas públicas na criação da Secretaria de Estado da Defesa Civil de Santa Catarina. 135 f. Dissertação (Mestrado em Gestão de Políticas Públicas) - Universidade do Vale do Itajaí (UNIVALI), Itajaí, SC.

Silveira, M. A. T.

2003. Turismo, políticas de ordenamento territorial e desenvolvimento: um foco no Estado do Paraná no contexto regional. Curitiba: Mídia.

Soares, J. G.; Cardoso, P. F.

2008. A avaliação e hierarquização de atrativos turísticos como ferramenta para o planejamento turístico.

São Paulo: Revista Partes.

Valls, J. F.

2006. Gestão integral de destinos turísticos sustentáveis. Rio de Janeiro: Editora FGV.

Recibido:

$22 / 02 / 2017$

Reenviado:

$03 / 09 / 2017$

Aceptado:

$05 / 11 / 2017$

Sometido a evaluación por pares anónimos 